\title{
Bax antisense oligonucleotides reduce axotomy-induced retinal ganglion cell death in vivo by reduction of Bax protein expression
}

\author{
Stefan Isenmann ${ }^{\star,}$, Stefan Engel ${ }^{1}$, Frank Gillardon ${ }^{2}$ and \\ Mathias Bähr ${ }^{1}$ \\ ${ }^{1}$ Department of Neurology, University of Tübingen, D-72076 Tübingen, \\ Germany \\ 2 Boehringer Ingelheim Pharma KG, 55216 Ingelheim, Germany \\ * corresponding author: Stefan Isenmann, Department of Neurology, University \\ of Tübingen Medical School, D-72076 Tübingen. Germany. tel: +49 7071/298 \\ 2141; fax: +49 7071/29 5260; e-mail: stefan.isenmann@tuebingen.mpg.de
}

Received 23.3.99; Received 3.5.99; Accepted 12.5.99

Edited by F. Miller

\begin{abstract}
Following transection of the optic nerve (ON), retinal ganglion cells (RGCs) upregulate Bax protein expression and undergo apoptosis. The present study aimed at reducing Bax expression in order to test whether Bax plays a causative role in the induction of secondary RGC apoptosis. Following injection into the vitreous, fluoresceinated oligonucleotides transfected RGCs in vivo at the injection site in the temporal superior retina. Following $\mathrm{ON}$ lesion, and repeated injections of a partially phosphorothioated Bax antisense oligonucleotide, but not following injection of control oligonucleotides, expression of Bax protein was locally inhibited, and the number of surviving RGCs was increased in Bax antisense treated rats 8 days after axotomy. Our results indicate that $B a x$ induction is a prerequisite for the execution of RGC apoptosis following ON axotomy. While the Bax antisense strategy offers an exciting perspective to inhibit secondary neuronal degeneration in vivo, both limited transfection efficacy, and the temporal restriction of this effect currently limit the use of this approach with respect to clinical applications for the treatment of neurodegeneration.
\end{abstract}

Keywords: apoptosis; cell death; gene transfer; neuroprotection; rat; retina

Abbreviations: DAPI, 4,6-diamino-2-phenylindole; F-ODN, fluoresceinated oligodeoxynucleotide; ON, optic nerve; RGC, retinal ganglion cell; SC, superior colliculus

\section{Introduction}

Following optic nerve (ON) lesion in rats, approximately $85 \%$ of the retinal ganglion cell (RGC) population die by apoptosis within 14 days. ${ }^{1-3}$ RGC death is maximal $6-8$ days following axonal injury, and is preceded by an early upregulation of the pro-apoptotic protein Bax in the same cell population. ${ }^{4}$ The temporal course of Bax upregulation and apoptotic RGC death, together with the known function of Bax as a Bcl-2 antagonising, cell death promoting activity, ${ }^{5}$ suggested a causal role of Bax overexpression in the induction of axotomyinduced RGC death. Further evidence for a crucial role of both $\mathrm{Bcl}-2$ and Bax proteins in regulating RGC survival comes from transgenic animals. While $\mathrm{Bcl}-2$ deficient mice have less RGCs than their wild-type littermates, ${ }^{6}$ mice overexpressing $\mathrm{Bcl}-2$ in RGCs from a NSE promoter have increased numbers of RGCs, ${ }^{7}$ and show enhanced RGC survival following ON axotomy. ${ }^{8}$ Likewise, in Bax knockout mice RGC numbers are increased. ${ }^{9}$

However, it has remained less clear if Bax plays a causative role in the induction of axotomy-induced RGC death in the adult organism. Thus, while immunocytochemical approaches allowed for a characterisation of the time course of regulatory events preceding RGC apoptosis, ${ }^{3,4}$ these studies did not prove a causative role of Bax overexpression in secondary RGC death. In the present study, we employed an in vivo antisense approach in order to address this question.

Transfection efficacy of RGCs was determined following injection of fluoresceinated oligonucleotides (F-ODNs) into the vitreous. In addition, F-ODNs were complexed with the liposome-forming agent, DOTAP, ${ }^{10,11}$ as well as with the cationic polymer, polyethyleneimine ${ }^{12,13}$ in order to examine if these reagents were able to enhance uptake of fluoresceinated ODNs by RGCs in vivo, as has been described in other experimental paradigms. We then examined if repeated administration of Bax antisense oligonucleotides (Bax antisense ODNs) was efficient to inhibit expression of Bax protein following ON lesion. Finally, we asked if Bax antisense ODNs - by blocking of Bax protein expression-increased RGC survival in response to ON axotomy.

\section{Results}

\section{Transfection efficacy}

Two hours following intravitreous injection of F-ODNs, few RGCs in the temporal superior middle (TSM) segment of the retina showed cytoplasmic fluorescein labelling (Figure $2 \mathrm{~A}$ ). The number of fluorescein-labelled RGCs increased with time and reached a maximum at 3 days. Thereafter, this number decreased again (Table 1; Figure $2 \mathrm{~A}-\mathrm{C}$ ). From $24 \mathrm{~h}$ following injection, RGCs displayed, in addition to cytoplasmic fluorescence, also nuclear fluorescence, indicating nuclear entry of the F-ODNs (Figure 2D-F). With the exception of few scattered cells, fluorescein labelled RGCs were exclusively present in the TSM segment of the retina, at approximately 3/6 to $4 / 6$ retinal radius, with no labelled cells in the other three 
retinal quadrants, nor in the adjacent temporal superior inner (TSI) or in the temporal superior outer (TSO) retinal segments. From 2 days after transfection, there was also fluorescence present in the $\mathrm{ON}$, indicating anterograde transport of the $\mathrm{F}$ ODNs (see below). As evaluated by means of conventional histology (H\&E; Nissl; DAPI), and GFAP immunochemistry, and by examination of flat mounted retinae, there were no toxic effects detectable for any of the ODNs employed (not shown).

Formation of cationic liposomes with DOTAP (Boehringer Mannheim) also resulted in efficient transfection, with numbers of transfected RGCs in the range of those after transfection of naked F-ODNs. With this technique, F-ODNs were preferentially located in the cytoplasm of RGCs, in cytoplasmic processes (Figure $3 A$ ), and particularly in RGC axons (Figure $3 \mathrm{~B}$ ). As with naked F-ODNs, axonal transport was observed, that resulted in the presence of fluorescent labelling in the ipsilateral ON (Figure $3 \mathrm{C}$ ), and contralateral optic tract (Figure 3D). In contrast, complexion of F-ODNs with $\mathrm{PEI}$ resulted in the formation of small spheroids that

Table 1 Numbers of F-ODN transfected RGCs

\begin{tabular}{llc}
\hline Time & $\boldsymbol{n}$ & Mean \pm S.E.M. \\
\hline $2 \mathrm{~h}$ & 4 & $51 \pm 30$ \\
$6 \mathrm{~h}$ & 4 & $95 \pm 40$ \\
$12 \mathrm{~h}$ & 4 & $160 \pm 32$ \\
$18 \mathrm{~h}$ & 4 & $170 \pm 42$ \\
1 day & 4 & $250 \pm 61$ \\
2 days & 4 & $278 \pm 130$ \\
3 days & 4 & $480 \pm 122$ \\
5 days & 4 & $243 \pm 103$ \\
7 days & 4 & $35 \pm 24$ \\
\hline
\end{tabular}

Numbers of fluorescein-labelled RGCs in the temporal superior retinal quadrant, middle segment (TSM) following a single intravitreous injection of $1 \mathrm{mM}$ F-ODN as analysed $2 \mathrm{~h}$ to 7 days after injection were stuck in the vitreous, and never yielded transfection of RGCs (Figure 3E).

These experiments demonstrated that the numbers of RGCs transfected in vivo using lipofection were very similar to those achieved with naked ODNs. However, since naked ODNs entered the nucleus more efficiently, and DOTAPcomplexed ODNs seemed to remain in the cytoplasm, and were axonally transported to considerable extent, further experiments were continued with naked ODNs.

\section{Bax antisense ODN inhibit overexpression of Bax protein}

The specificity of the Bax peptide antibodiy used in this study was demonstrated previously by protein blots, as well as by preabsorption with specific peptides. ${ }^{4,14,15}$ In the current study, sections in which the primary antibody was omitted were used as controls in every experiment and resulted in no background staining. In addition, staining patterns previously described for these antibodies ${ }^{14}$ were reproduced in normal adult rat brain (data not shown).

We have recently shown that Bax protein is overexpressed in RGCs following ON crush lesion. ${ }^{4}$ This upregulation of Bax protein expression was detected as early as $2 \mathrm{~h}$ following crush, and reached a maximum at 3 days post-lesion. Expression of Bax protein was upregulated throughout the entire retina in untreated rats (not shown; compare ${ }^{4}$ ). Repeated injections of control ODNs into the vitreous at the temporal half of the retina had no effect on Bax overexpression 3 days post-lesion in the nasal (Figure $4 \mathrm{~A}$ and $\mathrm{B}$ ) nor in the temporal half of the retina (Figure $4 C$ and $D$ ). In contrast, repeated injections of Bax antisense ODNs markedly reduced Bax protein expression after $\mathrm{ON}$ crush lesion in the temporal half of the retina (where Bax antisense ODNs were injected; Figure $4 \mathrm{G}$ and $\mathrm{H}$ ), but not in the nasal half (Figure $4 \mathrm{E}$ and
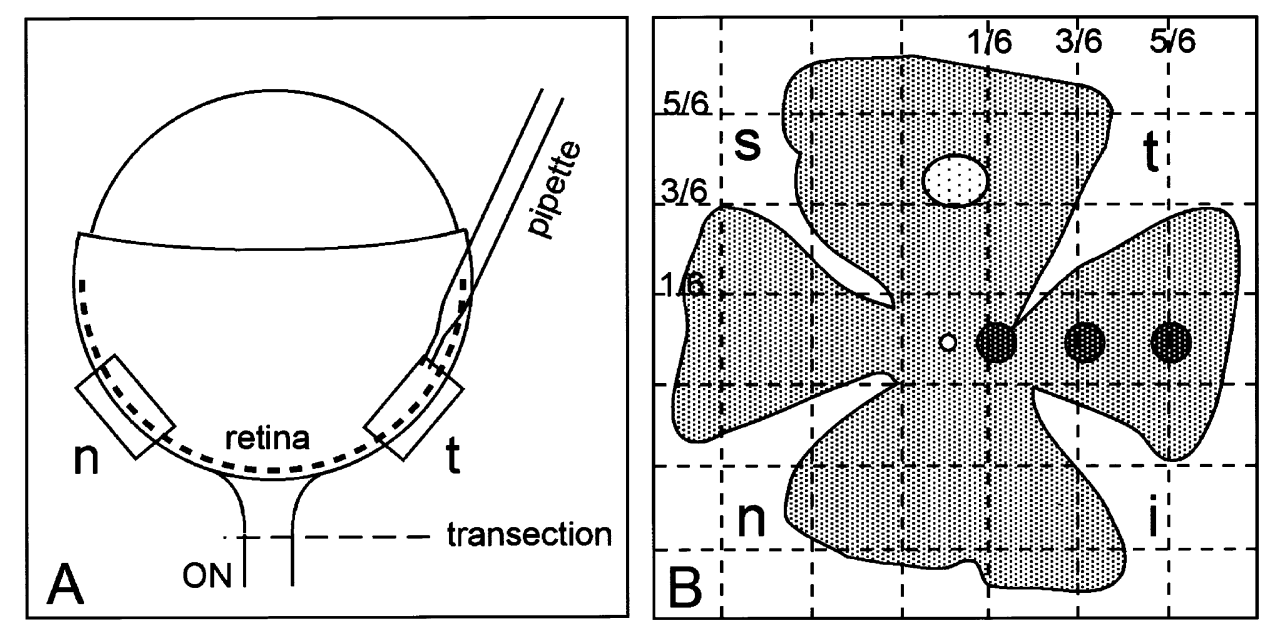

Figure 1 Experimental setup. (A) Injection technique. A glass pipette is inserted into the eye at the temporal half of the retina (dotted line) at the ora serrata, and ODNs are deposited into the vitreous at approximately 3-4/6 retinal radius. Squares indicate the regions that were examined immunocytochemically for Bax expression following ON lesion (compare Figure 4). (B) RGC counts on flat mounted retinae. For flat mounting, incisions were made at the temporal (t), nasal (n), superior (s), and inferior (i) face, and the retina thus divided in four quadrants (temporal superior, TS; temporal inferior, TI; nasal superior, NS; and nasal inferior, $\mathrm{NI}$ ). Labelled RGCs (Tables 2 and 3 ) were counted at $1 / 6,3 / 6$, and $5 / 6$ retinal eccentricity (shown as three dark circles for the TI quadrant). F-ODNs were only seen in the TS quadrant, at approximately $3-4 / 6$ retinal radius (bright circle) 
F). However, this reduction of Bax protein expression was incomplete and locally restricted to a circumscribed segment at the injection site in the TSM segment of the retina (compare Figure 1). At both, 5 and 7 days after $O N$ crush, Bax protein expression in the temporal retina was indistinguishable from untreated and control ODN treated retina following $\mathrm{ON}$ crush, indicating that the reduction of Bax protein expression was only transient (not shown).

Immunoblot analysis of whole retina preparations 3 days following ON crush did not reveal a significant decrease in total Bax protein following ON crush, and injection of Bax antisense ODNs, as compared to untreated, or control ODN treated retinae (not shown).

\section{Total RGC survival at 8 and 14 days following ON transection}

In order to examine RGC survival following ON lesion, the ON was transected close to the eye bulb, and RGCs were retrogradely labelled with FB. In untreated animals, approximately $85 \%$ of the RGC population had degenerated 14 days following ON axotomy, comparable to the results of our previous studies. ${ }^{16,17}$ These numbers were similar in both control ODN and Bax antisense ODN treated groups, with no statistical difference in total numbers of surviving RGCs (Table 2).

Likewise, 8 days following ON axotomy, no significant difference in overall RGC survival was detected between untreated, control ODN, and Bax antisense ODN treated animals. At this time point, approximately $60 \%$ of the total RGC population were still viable, comparable to the numbers reported by other groups. ${ }^{18,19}$ However, since at this time point many RGCs are undergoing apoptotic cell death, survival numbers varied considerably between individual animals (Table 2). Thus, in order to identify possible regionally limited effects of Bax antisense ODNs on RGC survival in the TSM segment, where ODNs were shown to be present and taken up by RGCs, we compared survival numbers in the TSM segment with numbers in other retinal segments in individual retinae.

\section{Regional RGC survival at the site site of Bax antisense ODN administration 8 and 14 days following ON transection}

Two ratios were calculated that related surviving RGCs in the TSM segment to surviving RGCs in the other retinal segments: ratio $(1)=\mathrm{TSM} /[(\mathrm{TIM}+\mathrm{NSM}+\mathrm{NIM}) / 3]$; ratio (2)=TSM/TSI (compare Materials and Methods; Table 3).

Eight days following ON axotomy, ratio (1) did not differ between untreated rats $(0.97 \pm 0.084)$, or rats treated with control ODNs $(1.02 \pm 0.14 ; P>0.05)$. In contrast, this ratio was significantly increased in rats treated with Bax antisense ODNs $(1.37 \pm 0.19 ; P<0.05)$. Likewise, ratio (2) did not differ between untreated rats $(0.75 \pm 0.06)$, or rats treated with control ODNs $(0.71 \pm 0.09 ; P>0.05)$, but was significantly increased in rats treated with Bax antisense ODNs $(0.96 \pm 0.06 ; P<0.05)$. However, this effect did not persist through the entire 14 days experimental period. At this time point, both ratio (1) $[1.082 \pm 0.110$ for untreated controls; $1.031 \pm 0.131$ for rats treated with control ODNs; $1.356 \pm 0.029$ for rats treated with Bax antisense ODNs; $P>0.05]$, and ratio (2) [0.983 \pm 0.097 for untreated controls; $0.847 \pm 0.107$ for rats treated with control ODNs; $0.823 \pm 0.072$ for rats treated with Bax antisense ODNs; $P>0.05]$, failed to yield a significant increase of surviving
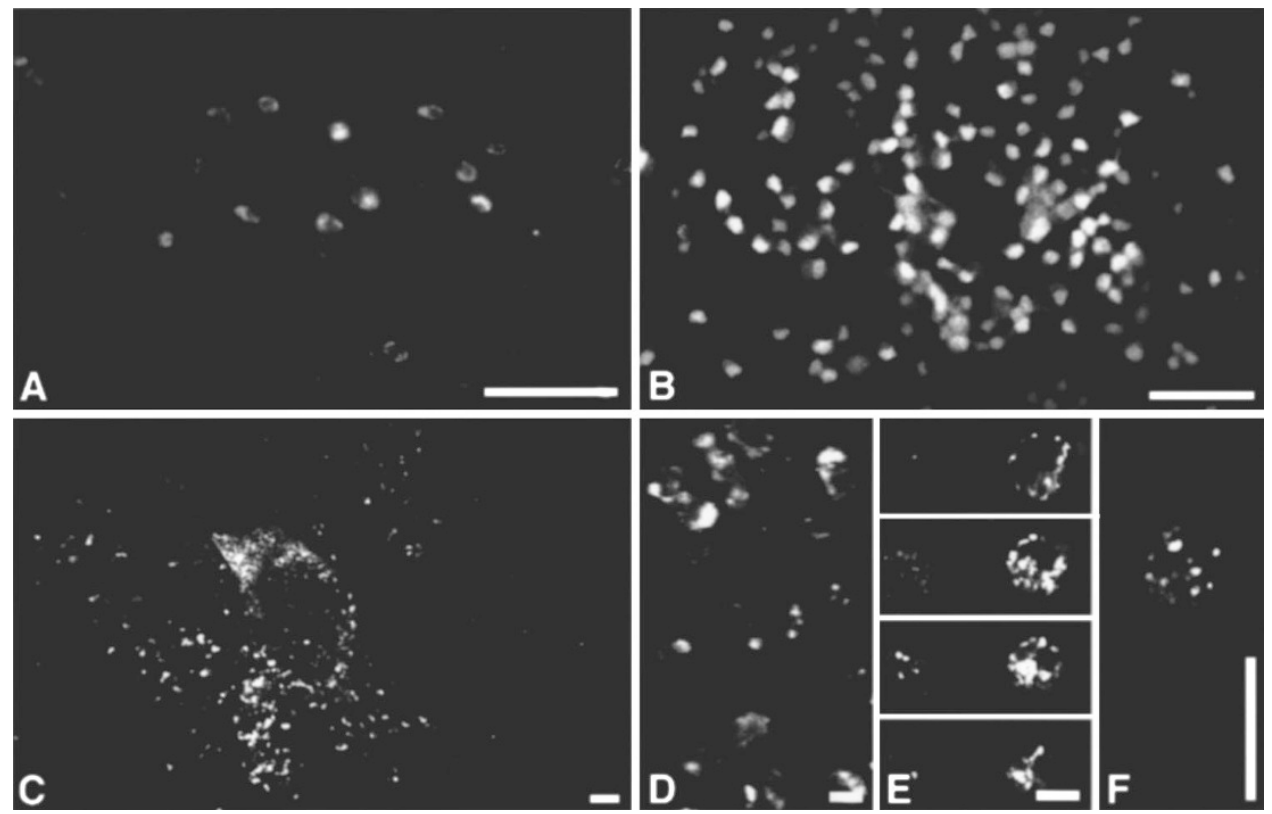

Figure 2 RGC transfection by naked F-ODN. (A) Six hours after injection, relatively few RGCs are transfected; (B) $24 \mathrm{~h}$ after injection, a larger number of RGCs has incorporated F-ODNs; (C) shows the overall extent and distribution of labelled RGCs at this time point. (D, E, F) subcellular localisation in the cytoplasm (D, E), and nucleus (F) of RGCs. E, F are confocal images. Scale bars, $100 \mu \mathrm{m}$ in $\mathbf{A}, \mathbf{B}, \mathbf{C} ; 10 \mu \mathrm{m}$ in D, E, F 
RGCs in the Bax antisense ODN treated group (Table 3). These data indicate that, in spite of variability in overall survival numbers between different retinae, Bax antisense ODNs specifically reduced axotomy-induced RGC death at the site of injection in a temporally restricted manner. Thus Bax antisense ODNs not only blocked Bax protein expression following ON lesion locally, but also reduced RGC death in vivo.

\section{Discussion}

In the present study, we examined the ability of ODN to transfect RGCs in vivo. We then investigated the effects of Bax antisense ODNs on axotomy-induced upregulation of Bax protein expression in RGCs and on RGC survival. Bax antisense ODNs focally and transiently inhibited overexpression of Bax protein following $\mathrm{ON}$ lesion, thereby delaying secondary RGC death.

\section{Transfection of RGCs by ODN in vivo}

RGCs were readily transfected by injection of naked F-ODNs into the vitreous. Following a single injection, F-ODNs were detected intracellularly in RGCs within a few hours, and fluorescence was present within these cells for up to 5 days (Figure 2A-C; Table 1). Thus, cell entry was retarded as compared to the uptake kinetics of the same F-ODNs in neurons in vitro, ${ }^{20}$ or injection of F-ODNs into the brain. ${ }^{21,22}$ Slower uptake of ODNs by RGCs as compared to neurons in the striatum is most likely due to the biological barrier of the glia limitans present in the retina.
While transduction with adenoviral vectors, that were injected into the vitreous using the same technique, infected mainly Müller glial cells, and only a minor proportion of neurons, ${ }^{17,23}$ F-ODNs transfected almost exclusively RGCs, and no fluorescein-labelled glial cells were identified as evaluated by exclusive location of labelled cells in the RGC layer of the retina, and on the size and morphology of fluorescein labelled RGCs. This is in keeping with other studies that showed that naked fluoresceinated ODNs injected into the caudoputamen were efficiently incorporated by neurons, and only to a much lesser extent by glial cells. ${ }^{22,24}$

Initially, F-ODNs were distributed rather homogeneously throughout the cytoplasm of transfected RGCs (Figure 2A and $\mathrm{B}$ ). From $12 \mathrm{~h}$ on, staining was more punctuate (Figure $2 \mathrm{D}$ and $\mathrm{E}$ ), and from $24 \mathrm{~h}$ after transfection, in addition to cytoplasmic distribution, F-ODNs were also localised in the nucleus of transfected RGCs (Figure 2F). This observation is similar to findings in neurons in vitro, ${ }^{20}$ and in other CNS regions in vivo, ${ }^{22}$ where-again, with faster kinetics-it was shown that transfected F-ODNs initially display homogeneous cytoplasmic distribution that is later followed by a more punctuate staining, most likely reflecting localisation in endocytic vesicles, and eventually nuclear staining. ${ }^{20,22}$

The liposome-forming agent, DOTAP, did not enhance uptake of F-ODNs by RGCs. While total numbers of transfected RGCs were similar to the numbers achieved with naked F-ODNs, following complexion with DOTAP, FODNs were present to a higher extent in the cytoplasm, and in cellular processes of transfected cells (Figure $3 \mathrm{~A}$ and $B$ ). This finding is in agreement with other reports
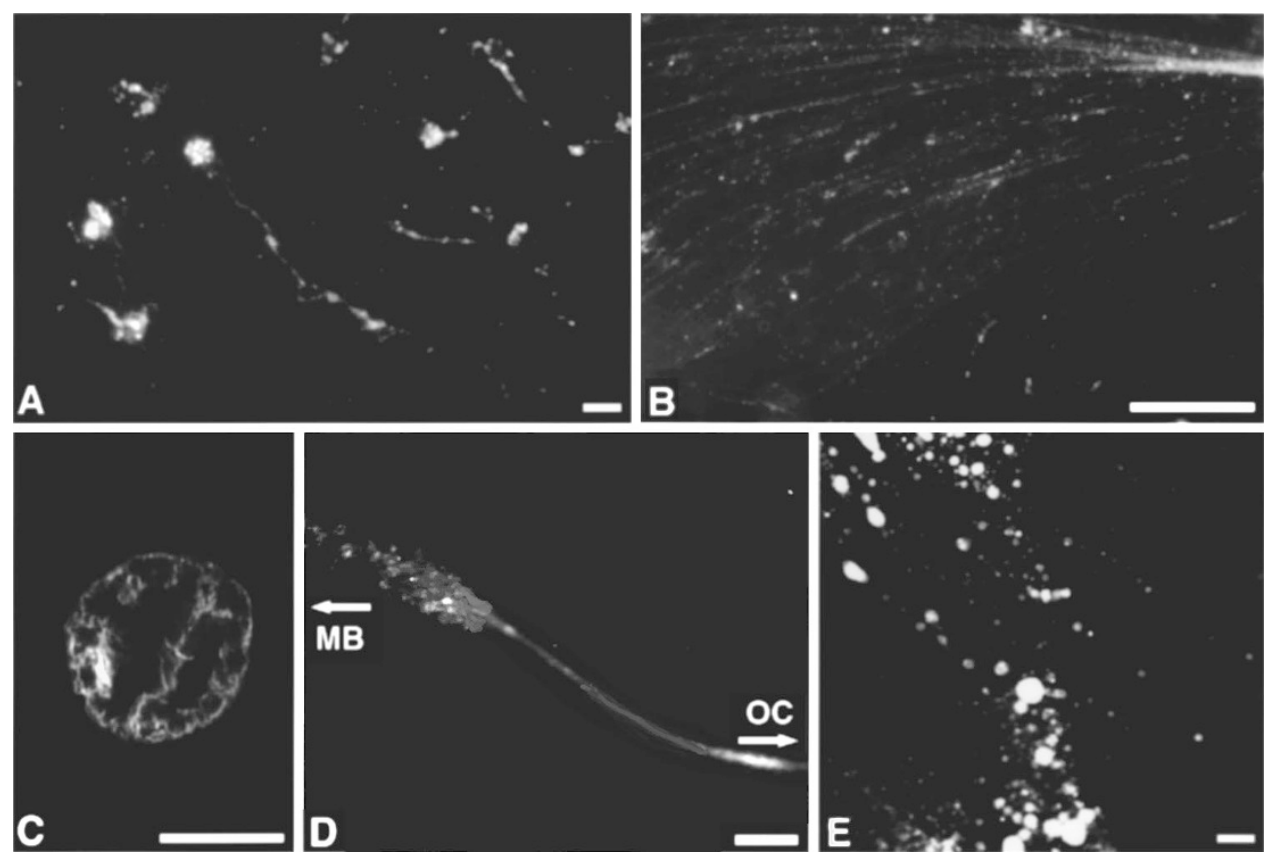

Figure 3 Transfection of RGCs following complexion with DOTAP or PEI. (A) The liposome-forming agent, DOTAP, led to efficient transfection of RGCs in vivo, with marked distribution of F-ODNs in the cytoplasm, and cellular processes, as well as in RGC axons (B). (C) cross section of the ipsilateral ON, and (D) longitudinal section of the contralateral optic tract demonstrating anterograde axonal transport of F-ODNs particularly following this transfection method. (Orientation: to MB, midbrain; to OC, optic chiasm). (E) pre-incubation with PEI prevents F-ODNs from efficient cell entry; spheroids represent complexed F-ODNs captured at the vitreal surface. Scale bars, $20 \mu \mathrm{m}$ in A, E; $500 \mu \mathrm{m}$ in B, C; $1 \mathrm{~mm}$ in D 

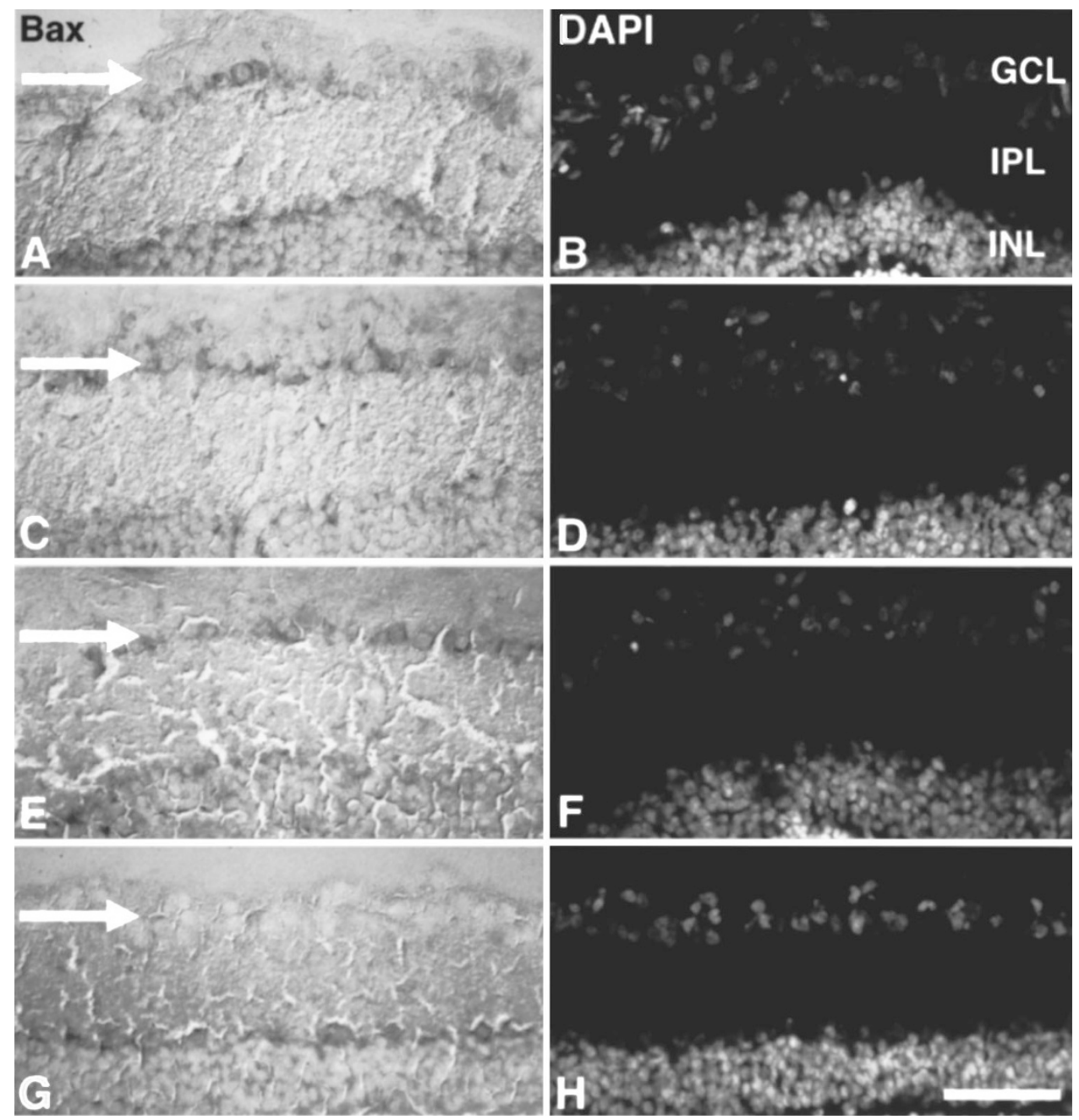

Figure 4 Suppression of Bax protein expression by Bax antisense ODN. Bax immunocytochemistry $(\mathbf{A}, \mathbf{C}, \mathbf{E}, \mathbf{G})$ and corresponding DAPI counterstaining for nuclear morphology (B, D, F, H). A, B, nasal, and C, D, temporal retina of a control ODN treated rat. E, F, nasal, and $\mathbf{G}, \mathbf{H}$, temporal retina of a Bax antisense ODN treated rat. Bax protein is expressed in RGCs 3 days following ON crush lesion in the nasal retina in control $(\mathbf{A})$ and Bax antisense treated (E) rats. Treatment with control ODNs also does not reduce Bax protein expression in RGCs in the temporal retina (C), whereas Bax antisense ODN treatment transiently and focally abrogates Bax protein expression in RGCs (G). Note the presence of Bax immunolabelling in cells of the inner part of the INL, which can be taken as an internal positive control (A, C, E, G). Scale bar, $50 \mu \mathrm{m}$ for $\mathbf{A}-\mathbf{H}$

Table 2 Total RGC numbers 8 and 14 days following ON axotomy, and administration of ODN

\begin{tabular}{|c|c|c|c|c|}
\hline & 1/6 Retinal radius & 3/6 Retinal radius & 5/6 Retinal radius & Average \\
\hline Normal control (unoperated) & $2726 \pm 104$ & $2312 \pm 61$ & $1213 \pm 48$ & $\begin{array}{c}2084 \pm 59 \\
(n=8)\end{array}$ \\
\hline Axotomy w/o treatment (14 days) & $485 \pm 21$ & $426 \pm 29$ & $291 \pm 20$ & $\begin{array}{c}401 \pm 20 \\
(n=4)\end{array}$ \\
\hline co ODN (14 days) & $481 \pm 22$ & $419 \pm 23$ & $233 \pm 19$ & $\begin{array}{c}378 \pm 18 \\
(n=4)\end{array}$ \\
\hline Bax-antisense ODN (14 days) & $502 \pm 38$ & $351 \pm 23$ & $238 \pm 26$ & $\begin{array}{c}364 \pm 28 \\
(n=4)\end{array}$ \\
\hline Axotomy w/o treatment (8 days) & $1154 \pm 179$ & $1009 \pm 94$ & $608 \pm 151$ & $\begin{array}{c}923 \pm 114 \\
(n=5)\end{array}$ \\
\hline co ODN (8 days) & $1323 \pm 101$ & $986 \pm 158$ & $526 \pm 179$ & $\begin{array}{c}945 \pm 118 \\
(n=4)\end{array}$ \\
\hline Bax-antisense ODN (8 days) & $1247 \pm 242$ & $1031 \pm 130$ & $587 \pm 166$ & $\begin{array}{c}955 \pm 177 \\
(n=4)\end{array}$ \\
\hline
\end{tabular}

RGC numbers 8 and 14 days, respectively, after ON axotomy, and either no treatment, administration of control ODNs, or administration of Bax-antisense ODNs in the adult rat. All values $(1 / 6 ; 3 / 6 ; 5 / 6$; average) were tested for intergroup significancy by ANOVA. Neither at 14 nor at 8 days, RGC numbers differed significantly between the three groups (no treatment; control ODNs; Bax antisense ODNs) 
Table 3 Temporally and locally restricted rescue of RGCs following ON axotomy, and administration of Bax antisense ODN

\begin{tabular}{|c|c|c|c|c|c|}
\hline & TSM & $(\mathrm{TIM}+\mathrm{NSM}+\mathrm{NIM}) / 3$ & $\begin{array}{c}\text { Ratio (1) } \\
\text { TSM/[(TIM+NSM+NIM)/3] }\end{array}$ & TSI & $\begin{array}{l}\text { Ratio (2) } \\
\text { TSM/TSI }\end{array}$ \\
\hline Axotomy w/o treatment (14 days) & $28 \pm 1.44$ & $26 \pm 2.29$ & $1.082 \pm 0.110$ & $29 \pm 4.01$ & $\begin{array}{c}0.983 \pm 0.097 \\
(n=4)\end{array}$ \\
\hline co ODN (14 days) & $27 \pm 3.07$ & $26 \pm 1.77$ & $1.031 \pm 0.131$ & $31 \pm 1.80$ & $\begin{array}{c}0.847 \pm 0.107 \\
(n=4)\end{array}$ \\
\hline Bax-antisense ODN (14 days) & $27 \pm 1.44$ & $20 \pm 1.48$ & $1.356 \pm 0.029$ & $34 \pm 3.01$ & $\begin{array}{c}0.823 \pm 0.072 \\
(n=4)\end{array}$ \\
\hline Axotomy w/o treatment (8 days) & $61.6 \pm 4.4$ & $63.5 \pm 6.8$ & $0.97 \pm 0.084$ & $82.8 \pm 7.7$ & $\begin{array}{c}0.75 \pm 0.06 \\
(n=5)\end{array}$ \\
\hline co ODN (8 days) & $62.3 \pm 12.8$ & $61.4 \pm 10.6$ & $1.02 \pm 0.14$ & $87.5 \pm 7.8$ & $\begin{array}{c}0.71 \pm 0.09 \\
(n=4)\end{array}$ \\
\hline Bax-antisense ODN (8 days) & $67.6 \pm 13.2$ & $61.5 \pm 8.4$ & $1.37 \pm 0.19^{\star}$ & $84 \pm 12.9$ & $\begin{array}{c}0.96 \pm 0.06^{*} \\
(n=4)\end{array}$ \\
\hline
\end{tabular}

Effects of intraocular administration of Bax-antisense ODNs, and control ODNs on RGC survival 8 and 14 days after ON crush: subgroup analysis. Numbers of labelled RGCs were counted in the temporal superior middle (3/6) segment (TSM) and analyzed against the average of the three other middle quadrants (temporal inferior, nasal superior and inferior (TIM, NSM, NIM): ratio (1). In addition, TSM was tested against the adjacent temporal superior inner segment (TSI), where no ODNs were present: ratio (2). All single values e.g., TSM, [(TIM+NSM+NIM)/3], TSI etc. were tested by ANOVA. While all the other values failed to show significant differences, both ratio (1) and ratio (2) did show a significant difference between Bax antisense ODN treated and both, control ODN treated, and untreated retinae at 8 days $\left({ }^{*} P<0.05\right)$, but not 14 days after $\mathrm{ON}$ axotomy $(P>0.05)$

indicating that in the mature CNS, and the visual system in particular, cellular uptake of ODNs and DNA by neurons is achieved relatively easily after administration of naked nucleic acids. ${ }^{21,22,24-29}$ Although intracellular fluorescence does not necessarily indicate the presence of intact F-ODN, there is ample evidence to suggest that this is indeed the case. Thus, Sommer et al. ${ }^{22}$ found that free FITC did not stain any structures in the brain, and Leonetti et al. ${ }^{30}$ reported that fluorescein alone is not taken up by cells and, following degradation and cleavage of oligonucleotides it is rapidly excluded from both the cytoplasm and the nucleus. Moreover, intact ODNs were recovered, and shown to remain stable in cells in the CNS, and in the CSF in vivo for at least $24 \mathrm{~h}^{22,26,31}$

Complexion of nucleic acids with cationic liposomes, while not enhancing neuronal uptake, resulted in increased transfection of glial cells by enhancing endocytic uptake, ${ }^{22}$ thus hinting to a different mechanism of cellular uptake in neurons as compared to glia, the neuronal one being more efficient. In contrast to CNS neurons, liposome encapsulation seems to greatly enhance transfection efficacy in peripheral tissues such as the lung, or arteries. ${ }^{32,33}$ The mechanisms underlying this different susceptibility to gene transfer agents in different cells and tissue types remain to be clarified.

In the present study, F-ODNs have been found to be anterogradely transported in RGC axons, and this phenomenon was particularly obvious if DOTAP was used for transfection (Figure $3 C$ and D). Anterograde transport of ODNs has also been reported in the striato-nigral pathway. ${ }^{21}$ In the visual system, this route of transport might be exploited further to interfere with gene expression in the targets of retinal axons, the geniculate nucleus, and the SC, without directly injecting into those structures.

\section{Transient inhibition of Bax protein expression by Bax antisense ODN}

Bax protein expression is induced in RGCs by ON lesion, and precedes RGC apoptosis. ${ }^{4}$ Induction of Bax protein expres- sion was detected from $2 \mathrm{~h}$ after $\mathrm{ON}$ crush lesion in untreated rats and in rats treated with control ODNs, and remained high for approximately 5 days (compare Figure 4A and C). In Bax antisense ODN treated rats, however, this picture was different. While ON crush induced Bax expression in the nasal retina, where no ODN were injected (Figure 4E), this expression was almost completely abrogated three days following $\mathrm{ON}$ crush in a circumscribed area in the temporal retina, where Bax antisense ODN were injected (Figure 4G; compare Figure 1). This effect was transient, and no more detectable 5 and 7 days after ON crush. Likewise, by means of immunochemistry, c-Fos protein expression has been shown to be reduced several hours following repeated injection of c-fos antisense ODN into the hippocampus of mice followed by brightness discrimination training. ${ }^{24}$

Protein blot analysis did not show any difference between levels of Bax protein in retinae either untreated, treated with control ODNs, or retinae treated with Bax antisense ODNs, as analysed 3 days after ON crush. This is most likely due to the fact that only a limited number of RGCs were transfected at the site of ODN deposition in the temporal retina. While RGCs make up only a small proportion of the total retinal cell population (approximately $1 \%$ ), suppression of Bax induction in only a subset of these results in a negligible reduction of the total amount of Bax protein as related to the entire retina. We did not examine Bax mRNA levels in retinae following transfection with Bax antisense ODNs. However, while-for the same reasons as with protein blot experiments - it would be very difficult to detect a lowering in Bax mRNA levels even if it were present, other studies in the CNS indicated that antisense ODNs, even if biological effects can unequivocally be demonstrated, usually do not reduce respective RNA levels, but rather seem to display their action by reducing the amount of protein at the level of translation. $^{21,34}$ Similar findings have been reported for the Bax antisense ODN employed in the present study in previous in vitro experiments. ${ }^{20}$ Taken together, these findings indicate that the partially phosphorothioated Bax antisense 
ODN employed in the present study exerted specific effects by reducing Bax protein expression in vivo, while no nonspecific effects were observed.

\section{Transient and locally restricted reduction of axotomy-induced RGC apoptosis by Bax antisense ODN}

Repeated injection of Bax antisense ODNs before and up to 4 days after $O N$ transection did not reduce the overall extent of secondary RGC death either 14 or 8 days following ON axotomy (Table 2). While both ratio (1) and ratio (2) (compare Materials and Methods) failed to show a significant increase in the number of surviving RGCs 14 days following ON axotomy, both were significantly increased 8 days after ON axotomy (Table 3). Therefore, focal inhibition of axotomy-induced Bax protein induction reduced secondary RGC death in a locally and temporally restricted manner. Since even repeated injection of Bax antisense ODNs reduced expression of Bax protein merely at the injection site, it comes as no surprise that the effect of Bax antisense ODNs on secondary RGC death is only a localised one, and does not influence the total number of surviving RGCs in the entire retina. Also, it is conceivable that even this localised effect is transient, since ODNs have been shown to be stable in the CNS for no longer than 24$48 \mathrm{~h} .{ }^{22,26,31}$ In this context, it is also worth remembering that all experimental strategies that aimed at reducing axotomyinduced RGC death established so far have only been transiently efficient. ${ }^{16,17,23,29}$

The overall effect of Bax antisense ODNs was moderate, which might be explained by the relatively small number of RGCs that is transfected in the first place, and by the assumption that repeated injections will not necessarily transfect the same RGCs again and again. Increasing the number of injections to more than five or six would not be feasible, since this increases the risk of tissue damage, and infection. One way to overcome this problem could be continuous infusion of ODNs. This task has successfully been completed in the brain, and lateral ventricles. ${ }^{34,35}$ However, for technical reasons implantation of an osmotic minipump is not feasible in the rat eye.

Our results indicate that the induction of Bax protein expression in response to axonal injury not only precedes RGC apoptosis, but is indeed causally involved in secondary RGC degeneration, since focal deterioration of Bax expression postpones RGC apoptosis. Most likely, Bax exerts its cell death promoting action via both homodimerisation and heterodimerisation with antiapoptotic members of the Bcl-2 family of proteins. ${ }^{36}$ Recent evidence indicates that death signals induce homodimerisation of Bax protein, that is followed by translocation of Bax from the cytosol to mitochondria, mitochondrial dysfunction, and apoptosis. ${ }^{37,38}$ However, Bax overexpression alone might not be sufficient to induce RGC apoptosis, since in transgenic mice that constitutively express Bax protein in RGCs from a NSE promotor display no obvious reduction of RGC numbers. ${ }^{39}$

On the other hand, Bax-deficient neurons show increased resistance to apoptotic stimuli such as NGF withdrawal despite the presence of the pro-apoptotic proteins Bad and Bid. Therefore, Bax appears to be a key apoptotic modulator in neurons. Furthermore, biochemical analyses placed Bax upstream of the cellular commitment to apoptosis, and cytochrome $\mathrm{C}$ release-as opposed to caspases, which have been shown to act further downstream. ${ }^{40,41}$ These properties make Bax an attractive target for neuroprotective strategies, since it is conceivable that blockage of the cell death cascade at an early point preserves cellular requirements for functional recovery, and regeneration. In the retina, both the limited number of transfected RGCs, and only transient reduction of Bax expression seem to be limiting factors. However, with respect to therapeutic strategies, these restrictions might be overcome in other CNS regions by delivery of antisense molecules to neurons in vivo by continuous infusion, ${ }^{34,35}$ or the use of viral vectors for delivery. ${ }^{17,23,42,43}$

\section{Materials and Methods}

\section{Oligonucleotides}

A $5^{\prime}$-fluoresceinated oligonucleotide, a partially phosphorothioated Bax antisense oligonucleotide, and a control oligonucleotide were used as described previously. ${ }^{20}$ ODNs with partially phosphorothioate-modified internucleoside backbones were synthesised on an $A B I$ 380B DNA synthesizer as described before. ${ }^{20,44}$ Crude ODNs were purified by FPLC on Q-Sepharose (Pharmacia) and desalted by ultrafiltration via Minitan 3000 (Millipore). The crude ODNs were characterised as ammonium salts and converted to sodium salts prior to administration. ODNs were used as follows (asterisks show sites of phosphorothioate modification): the Bax antisense ODN (5'$T^{\star} G^{*} C T^{\star} C C^{\star} C^{\star} C G G A C^{\star} C^{*} C G T^{\star} C C^{*} A^{\star} T-3^{\prime}$ ) was complementary to the translation initiation site of bax mRNA; for control purposes, a mismatch control $\left(5^{\prime}-T^{*} C^{*} G T^{\star} C C^{*} G^{*} G C C A C^{*} C^{*} G C T^{\star} C A^{*} C^{*} T-3^{\prime}\right)$ was used which had little complementarity to bax mRNA, but the same base composition as the antisense ODN. ${ }^{5,20}$ For the present study, ODN lyophilisates were dissolved in sterile water and both the Bax antisense ODN and the control ODN were used at a concentration of $1 \mathrm{mM}$.

\section{Animal procedures}

All animal procedures were carried out according to the German animal protection laws and the European Communities Council Directive of 24 November 1986 (86/609/EEC).

\section{Administration of ODN in vivo}

Rats were anaesthetised by diethylether. By means of a glass microelectrode with a tip diameter of approximately $30 \mu \mathrm{m}, 1 \mu \mathrm{L}$ of ODNs were injected into the vitreous body posterior to the ora serrata. The ODNs were deposited at approximately $3 / 6$ retinal radius in the temporal superior retinal quadrant. For studies on cellular uptake, $5^{\prime}$ fluorescein-labelled control ODNs ${ }^{20}$ were used and injected into the vitreous. In a first series of experiments, naked fluoresceinated ODNs were used at $1 \mathrm{mM}(1 \mu \mathrm{L})$. Injected rats were sacrificed at various time points, ranging from $2 \mathrm{~h}$ up to 7 days following injection, and the retinae examined under epifluorescence for the presence of fluorescein-labelled cells (compare Table 1 Figure 1).

In further experiments, fluoresceinated ODNs were complexed with the liposome-forming agent, DOTAP (N-[1-(2,3-Dioleoyloxy)propyl]- 
$\mathrm{N}, \mathrm{N}, \mathrm{N},-$ trimethylammonium methylsulphate; Boehringer Mannheim, Germany), ${ }^{45}$ to examine if these complexes were able to transfect RGCs more efficiently. The DOTAP/ODN- mixture was prepared as suggested by the manufacturer. A DNA-/DOTAP-ratio of $1: 3-1: 6$ was chosen, since this has been found to give optimum transfection results in previous studies. ${ }^{10,11}$

Finally, fluoresceinated ODNs were complexed with the cationic polymer, polyethylenimine ( $\mathrm{PEI}, 25 \mathrm{kDa}$; Aldrich, Milwaukee, USA), and the efficiacy of RGC transfection examined. PEI has been suggested as an efficient tool for gene transfer in vitro, and to the embryonic CNS in vivo. ${ }^{12}$ DNA was complexed with $\mathrm{PEI}$ at a ratio of 1 PEI nitrogen per DNA phosphate as described in detail elsewhere. ${ }^{46}$

\section{Optic nerve crush and transection}

The optic nerve was crushed or transected in adult female SPRD rats (240-280 g; 3-4 months old) as described in detail elsewhere. . $^{3,17}$ Briefly, rats were anaesthetised with chloral hydrate $7 \%$ in PBS $420 \mathrm{mg} / \mathrm{kg}$ body weight). For ON crush lesions, the left eye bulb was mobilised and the optic nerve crushed between the branches of watchmaker's forceps for $15 \mathrm{~s}$, at a distance of approximately $0.5 \mathrm{~mm}$ from the eye as described. ${ }^{4}$ For $O N$ transection, a skin incision was made close to the superior orbital rim and the right orbita was opened. After subtotal resection of the lacrimal gland, the superior extraocular muscles were spread. The ON was exposed and was transected at a distance of $2 \mathrm{~mm}$ from the eye bulb. Care was taken not to injure the eye or impair the blood supply. The bulb was placed back into the orbita and the intactness of the retinal blood supply checked by fundoscopy. ${ }^{17}$ Operated animals were monitored until they were awake and moved spontaneously. RGCs were retrogradely labelled with the fluorescent tracers $1,1^{\prime}$-dioctadecyl-3,3,3',3'-tetramethylindocarbocyanine perchlorate (Di-l; Molecular Probes Inc., Oregon, USA) and Fast Blue (FB; Dr. Illing Chemie, Germany). Di-I (5\% in DMF) was applied by a micropipette to both superior colliculi on postnatal day 5. For FB staining, a small piece of gel foam soaked in $2 \%$ aequous FB was placed at the ocular stump of the ON after axotomy. Double staining protocols with Di-I and FB revealed similar labelling efficacies of the two tracers, therefore allowing for comparison of $\mathrm{Di}-\mathrm{I}$ and FB data. ${ }^{17,47}$

\section{Experimental design}

For examination of Bax protein expression following $\mathrm{ON}$ crush, control or antisense ODNs, respectively, were repeatedly injected into the vitreous (at 24 and $8 \mathrm{~h}$ before ON crush, immediately after ON crush, and 12 and $24 \mathrm{~h}$ after $\mathrm{ON}$ crush). For evaluation of RGC numbers 8 and 14 days after ON axotomy, control or antisense ODNs, respectively, were injected into the vitreous at 24 and $8 \mathrm{~h}$ before $\mathrm{ON}$ axotomy, immediately after ON axotomy, and 12, 24, 48 and $96 \mathrm{~h}$ after ON axotomy.

\section{Immunocytochemistry}

For retina analysis, animals received an overdose of chloral hydrate. The eyes were removed and immediately snap frozen. $16 \mu \mathrm{m}$ cryostat sections were cut, and processed for immunocytochemistry as described previously. ${ }^{4,14,15}$ Briefly, sections were air dried, incubated in $10 \%$ normal goat serum, followed by a polyclonal rabbit antiserum to Bax $(1: 500) .{ }^{4,14,15}$ Signals were visualised using a biotinylated goatanti-rabbit secondary antibody (1:300; Dianova, Hamburg, Germany) followed by incubation with an avidin-biotin-peroxidase-complex (Vector Laboratories, Burlingame, CA, USA), according to the manufacturer's instructions. Sections were processed with 3,3diaminobenzidine (DAB; $0.05 \%$ ) and $\mathrm{H}_{2} \mathrm{O}_{2}(0.015 \%)$ in $10 \mathrm{mM}$ Trisbuffer for 3-5 min and the reaction product visualised under a Zeiss microscope. To test specificity of Bax immunostaining, peptide competition experiments were carried out as described in detail elsewhere. ${ }^{4,14}$ For assessment of nuclear morphology, retinae were counterstained with DAPI (4,6-diaminido-2phenylindole). ${ }^{4}$

\section{Immunoblot analysis}

For Western Blot analysis, retinae were dissected 3 days after ON crush, and repeated injection of Bax-antisense ODNs, or control ODNs. The tissue was immediately homogenised in RIPA buffer containing protease inhibitors. ${ }^{14}$ After sonication on ice and centrifugation of debris, aliquots of protein samples $(50 \mu \mathrm{g}$ total protein) were analyzed by SDS -PAGE/immunoblotting (12\% gels) using $0.05 \%$ Bax specific preabsorbed antisera followed by $0.15 \mu \mathrm{g} / \mathrm{ml}$ biotinylated goat-anti-rabbit IgG and horseradish peroxidase avidinbiotin complex reagent (Elite, Vector) and then DAB for 20 min. ${ }^{14,15}$

\section{Tissue processing and evaluation of flat mounted retinae}

Rats were sacrificed by an overdose of chloral hydrate 8 or 14 days after ON transection, respectively. Retinae were dissected under a stereomicroscope, flat-mounted on glass slides, and fixed in 4\% PFA in PBS for $15 \mathrm{~min}^{16,17}$ For analysis of fluorescein-labelled cells following injection of fluoresceinated ODNs, rats were sacrificed at intervals ranging from $2 \mathrm{~h}$ to 7 days following injection. Retinae were examined under epifluorescence using a FITC filter (450-490/ $520 \mathrm{~nm}$ ), and thoroughly analysed by focusing through all retinal layers. Transfected cells were counted and evaluated.

For counting of surviving RGCs following ON transection, retinae were examined under epifluorescence using a rhodamine filter (546/ $590 \mathrm{~nm})$ for Di-I fluorescence, or a DAPI filter $(365 / 397 \mathrm{~nm})$ for FB fluorescence, respectively (Axiovert 35, Zeiss, Germany). RGC densities were determined by counting tracer-labelled RGCs in 12 distinct areas of $62,500 \mu \mathrm{m}^{2}$ each (three areas per retinal quadrant at $1 / 6,3 / 6$, and $5 / 6$ of the retinal radius; compare Figure 1). ${ }^{16,17,47}$ Cells were counted according to a double blind protocol, and all counts were performed in duplicate by two independent investigators.

\section{Statistical analysis}

Data are given as mean \pm standard error of the mean (S.E.M.). Statistical significance was assessed using ANOVA. In order to examine regional effects of Bax antisense ODNs on RGC survival in the temporal superior quadrant (TSM) of the retina two ratios were calculated that related surviving RGCs in the TSM to surviving RGCs in the three other quadrants at $3 / 6$ retinal radius (TIM, NSM, NIM): ratio (1) $=\mathrm{TSM} /[(\mathrm{TIM}+\mathrm{NSM}+\mathrm{NIM}) / 3]$, or to surviving RGCs in the adjacent temporal superior inner (TSI) segment (at $1 / 6$ retinal eccentricity), where no ODNs were present: ratio (2)=TSM/TSI (compare Tables 2 and 3).

\section{Acknowledgements}

This work was supported by the Deutsche Forschungsgemeinschaft (IS 64/1-1). We are grateful to Dr. E. Uhlmann, Hoechst AG, Frankfurt, for oligonucleotide synthesis, to E. Jost for techincal assistance, and to Drs J.C. Reed and S. Krajewski, The Burnham Institute, La Jolla, for the Bax antiserum. 


\section{References}

1. Garcia-Valenzuela E, Gorczyca W, Darzynkiewicz Z and Sharma SC (1994) Apoptosis in adult retinal ganglion cells after axotomy. J. Neurobiol. 25:431 - 438

2. Berkelaar M, Clarke DB, Wang YC, Bray GM and Aguayo AJ (1994) Axotomy results in delayed death and apoptosis of retinal ganglion cells in adult rats. J. Neurosci. 14: $4368-4374$

3. Isenmann S and Bähr M(1997) c-Jun protein is expressed in degenerating retinal ganglion cells after optic nerve lesion in the rat. Exp. Neurol. 147: 28-36

4. Isenmann S, Wahl C, Krajewski S, Reed JC and Bähr M (1997) Upregulation of Bax Protein in Degenerating Retinal Ganglion Cells precedes Apoptotic Cell Death after Optic Nerve Lesion in the Rat. Eur. J. Neurosci. 9: 1763-1772

5. Oltvai ZN, Milliman CL and Korsmeyer SJ (1993) Bcl-2 heterodimerizes in vivo with a conserved homolog, Bax, that accelerates programmed cell death. Cell 74: $609-619$

6. Cellerino A, Michaelidis T, Barski JJ, BährM, Thoenen Hand MeyerM(1999) Bcl2 deficient mice undergo a rapid wave of retinal ganglion cell degeneration following the period of naturally occuring cell death. NeuroReport in press

7. Bonfanti L, Strettoi E, Chierzi S, Cenni MC, Liu XH, Martinou JC, Maffei L and Rabacchi SA (1996) Protection of retinal ganglion cells from natural and axotomy-induced cell death in neonatal transgenic mice overexpressing bcl-2. J. Neurosci. 16: $4186-4194$

8. Cenni MC, Bonfanti L, Martinou JC, Ratto GM, Strettoi E and Maffei L (1996) Long-term survival of retinal ganglion cells following optic nerve section in adult bcl-2 transgenic mice. Eur. J. Neurosci. 8: 1735-1745

9. Mosinger Ogilvie J, Deckwerth TL, Knudson CM and Korsmeyer SJ (1998) Suppression of developmental retinal cell death but not of photoreceptor degeneration in Bax-deficient mice. Invest. Ophthalmol. Vis. Sci. 39: 17131720

10. Felgner PL, Gadek TR, Holm M, Roman R, Chan HW, Wenz M, Northrop JP, Ringold GM and Danielsen M (1987) Lipofection: a highly efficient, lipidmediated DNA-transfection procedure. Proc. Natl. Acad. Sci. USA 84: 74137417

11. Holt CE, Garlick N and Cornel E (1990) Lipofection of cDNAs in the embryonic vertebrate central nervous system. Neuron 4: 203-214

12. Boussif $O$, Lezoualc'h F, Zanta MA, Mergny MD, Scherman D, Demeneix B and Behr JP (1995) A versatile vector for gene and oligonucleotide transfer into cells in culture and in vivo: Polyethylenimine. Proc. Natl. Acad. Sci. USA 92: 7297 7301

13. Lambert RC, Maulet Y, DupontJL, Mykita S, Craig P, Volsen Sand Feltz A (1996) Polyethylenimine-mediated DNA transfection of peripheral and central neurons in primary culture: probing $\mathrm{Ca} 2+$ channel structure and function with antisense oligonucleotides. Mol. Cell. Neurosci. 7: 239-246

14. Krajewski S, Mai JK, Krajewska M, Sikorska M, Mossakowski MJ and Reed JC (1995) Upregulation of Bax protein levels in neurons following cerebral ischemia. J. Neurosci. 15: 6364-6376

15. Isenmann S, Stoll G, Schroeter M, Krajewski S, Reed JC and Bähr M (1998b) Differential regulation of $\mathrm{Bax}, \mathrm{Bcl}-2$, and $\mathrm{Bcl}-\mathrm{X}$ proteins in focal cortical ischemia in the rat. Brain Pathol. 8: 49-63

16. Klöcker N, Bräunling $F$, Isenmann S and Bähr M (1997) In vivo neurotrophic effects of GDNF on retinal ganglion cells. NeuroReport 8: $3439-3442$

17. Isenmann S, Klöcker N, Gravel C and Bähr M (1998a) Protection of axotomized rat retinal ganglion cells by adenovirally administered BDNF in vivo. Eur. J. Neurosci. 10: 2751-2756

18. Mansour Robaey S, Clarke DB, Wang YC, Bray GM and Aguayo AJ (1994) Effects of ocular injury and administration of brain-derived neurotrophic factor on survival and regrowth of axotomized retinal ganglion cells. Proc. Natl. Acad. Sci. USA 91: 1632-1636

19. Peinado Ramon P, Salvador M, Villegas Peres MP and Vidal Sanz M (1996) Effects of axotomy and intraocular administration of NT-4, NT-3, and brainderived neurotrophic factor on the survival of adult rat retinal ganglion cells. A quantitative study. Invest. Ophthalmol. Vis. Sci. 37: 489-500

20. Gillardon F, Zimmermann M, Uhlmann E, Krajewski S, Reed JC and Klimaschewski L (1996) Antisense oligonucleotides to bax mRNA promote survival of rat sympathetic neurons in culture. J. Neurosci. Res. 43: 726-734

21. Sommer W, Rimondini R, O'Connor W, Hansson AC, Ungerstedt $U$ and Fuxe $K$ (1996) Intrastriatally injected c-fos antisense oligonucleotide interferes with striatonigral but not striatopallidal $\gamma$-aminobutyric acid transmission in the conscious rat. Proc. Natl. Acad. Sci. USA 93: 14134-14139
22. Sommer W, Cui X, Erdmann B, Wiklund L, Bricca C, Heilig M and Fuxe K (1998) The spread and uptake pattern of intracerebrally administered oligonucleotides in nerve and glial cell populations of the rat brain. Antisense Ncl. Acid Drug Development 8: $75-85$

23. DiPolo A, Aigner LJ, Dunn RJ, Bray GM and Aguayo AJ (1998) Prolonged delivery of brain-derived neurotrophic factors by adenovirus-infected Muller cells temporarily rescues injured retinal ganglion cells. Proc. Natl. Acad. Sci. USA 95: 3978-3983

24. Grimm R, Schicknick H, Riede I, Gundelfinger ED, Herdegen T, Zuschratter W and Tischmeyer W (1997) Suppression of c-fos induction in rat brain impairs retention of a brightness discrimination reaction. Learn. Memory 3: 402-413

25. Wahlestedt C, GolanovE, Yamamoto S, Yee F, Ericson H, Yoo H, Inturrisi CE and Reis DJ (1993) Antisense oligonucleotides to NMDA-R1 receptor channel protect cortical neurons from excitotoxicity and reduce focal ischemic infarctions. Nature 363: $260-263$

26. Wahlestedt C (1994) Antisense oligonucleotide strategies in neuropharmacology (1994). Trends Pharmacol. Sci. 15: 42-46

27. Schwartz B, Benoist C, Abdallah B, Rangara R, Hassan A, Scherman D and Demeneix BA (1996) Gene transfer by naked DNA into adult mouse brain. Gene Therapy 3: 405-411

28. Garcia-Valenzuela E, Rayanande R, Perales JC, Davidson CA, Hanson RW and Sharma SC (1996) Axon-mediated gene transfer of retinal ganglion cells in vivo. J. Neurobiol. 32: 111-122

29. Garcia-Valenzuela E and Sharma SC (1998) Rescue of retinal ganglion cells from axotomy-induced apoptosis through trk oncogene transfer. NeuroReport 9: $3165-3170$

30. Leonetti J, Mechti N, Degols G, Gagnor C and Lebleu B (1991) Intracellular distribution of microinjected antisense oligonucleotides. Proc. Natl. Acad. Sci. USA 84: 2702-2706

31. Whitesell L, Geselowitz D, Chavany C, Fahmy B, Walbridge S, Alger JR and Neckers LM (1993) Stability, clearance, and disposition of intraventricularly administered oligodeoxynucleotides: implications for therapeutic application within the central nervous system. Proc. Natl. Acad. Sci. USA 90: 4665-4669

32. Stephan DJ, Yang ZY, San H, Simari RD, Wheeler CJ, Felgner PL, Gordon D, Nabel GJ and NabelEG (1996) A new cationic liposome DNA complex enhances the efficiency of arterial gene transfer in vivo. Human Gene Ther. 7: 1803-1812

33. Wheeler CJ, Felgner PL, Tsai YJ, Marshall J, Sukhu L, Doh SG, Hartikka J, Nietupski J, Manthorpe M, Nichols M, Plewe M, Liang XW, Norman J, Smith A and Cheng SH (1996) A novel cationic lipid greatly enhances plasmid DNA delivery and expression in mouse lung. Proc. Natl. Acad. Sci. USA 93: 11454-11459

34. Skutella T, Schwarting RKW, Huston JP, Sillaber I, Probst JC, Holsboer F and Spanagel R (1997) Infusions of tyrosine hydroxylase antisense oligodeoxynucleotides into substantia nigra of the rat-effects on tyrosine hydroxylase mRNA and protein content, striatal dopamine release and behaviour. Eur. J. Neurosci. 9: 210-220

35. Cui JK, Hsu CY and Liu PK (1999) Suppression of postischemic hippocampal nerve growth factor expression by a c-fos antisense oligodeoxynucleotide. J. Neurosci. 19: 1335-1344

36. Sedlak TW, Oltvai ZN, Yang E, Wang K, Boise LH, Thompsom CB and Korsmeyer SJ (1995) Muliple Bcl-2 family members demonstrate selective dimerisations with Bax. Proc. Natl. Acad. Sci. USA 92: 7834-7838

37. Gross A, Jockel J, Wie MC and Korsmeyer SJ (1998) Enforced dimerisation of Bax results in its translocation, mitochondrial dysfunction and apoptosis. EMBO J. 17: $3878-3885$

38. Green DR and Reed JC (1998) Mitochondria and apoptosis. Science 281: $1309-1312$

39. Bernard R, Dieni S, Rees S and Bernard O (1998) Physiological and induced neuronal death are not affected in NSE-bax transgenic mice. J. Neurosci. Res 52: $247-259$

40. Easton RM, Deckwerth TL, Parsadanian AS and Johnson EM (1997) Analysis of the mechanism of loss of trophic factor dependence associated with neuronal maturation: A phenotype indistinguishable from Bax deletion. J. Neurosci. 17 9656-9666

41. Deckwerth TL, Easton RM, Knudson CM, Korsmeyer SJ and Johnson EM (1998) Placement of the BCL2 family member BAX in the death pathway of sympathetic neurons activated by trophic factor deprivation. Exp. Neurol. 152: 150-162

42. Ali RR, Reichel MB, Dealwis M, Kanuga N, Kinnon C, Levinsky RJ, Hunt DM, Bhattacharya SS and Thrasher AJ (1998) Adeno-associated virus gene transfer to mouse retina. Human Gene Ther. 9: $81-86$ 
43. Naldini L (1998) Lentiviruses as gene transfer agents for delivery to non-dividing cells. Curr. Opin. Biotechnol. 9: 457-463

44. Jyer RP, Phillips LR, Egan W, Reagan JB and Beaucage SL (1990) The automated synthesis of sulfur-containing oligodeoxyribonucleotides using $3 \mathrm{H}-$ 1,2-benzodithiol-3-one 1,1-dioxide as a sulfur-transfer agent. J. Org. Chem. 55: 4693-4698

45. Stamatatos L, Leventis R, Zuckermann ML and Silvius JR (1988) Interactions of cationic lipid vesicles with negatively charged phospholipid vesicles and biological membranes. Biochemistry 27: 3917-3925
46. Abdallah B, Hassan A, Benoist C, Goula D, Behr JP and Demeneix BA (1996) A powerful nonviral vector for in vivo gene transfer into the adult mammalian brain: polyethylenimine. Human Gene Ther. 7: 1947-1954

47. Eschweiler GW and Bähr M (1993) Flunarizine enhances rat retinal ganglion cell survival after axotomy. J. Neurol. Sci. 116: 34-40 